\title{
The Effect of Using Movie Scripts as an Alter- native to Subtitles: How to Improve Listening Comprehension
}

\author{
Mehdi Latifi \\ Amin University \\ ManiJeh YouhanaEe \\ ELHAM MOHAMMADI \\ University of Isfahan
}

Received: 11 May 2012 / Accepted: 30 September 2012

ISSN: $1697-7467$

\begin{abstract}
This research was conducted to investigate the effect of using movie scripts on improving listening comprehension. Forty five intermediate learners were selected based on an IELTS test to carry out the study, and then they were divided into 3 groups: a Home Scripts Group (HSG), a Class Scripts Group (CSG), and a Non Scripts Group (NSG). Each group was required to transcribe a section of a movie entitled The Truman Show. The HSG had the scripts before starting to transcribe the section, the CSG received the scripts in the class, and the NSG received usual training without the scripts. Performance on the posttest revealed a significant difference among the groups with the best achievement for the CSG. More specifically, these differences indicated (a) using scripts may enhance L2 listening comprehension and (b) the most appropriate time of handing scripts to students seems to be after completion of the transcription task.
\end{abstract}

Keywords: Listening Comprehension, Movies, Scripts, Task performance, Transcription

El efecto del uso de guiones de películas como alternativa a subtítulos: cómo mejorar la comprensión auditiva

RESUMEN: Esta investigación se llevó a cabo para conocer el efecto del uso de guiones de cine en la mejora de la comprensión auditiva. Para ello fueron seleccionados sobre la base de un examen IELTS, 45 alumnos de nivel intermedio que se dividieron en 3 grupos: Inicio Scripts Group (HSG), Scripts Class Group (CSG), y no Scripts Group (NSG). Cada grupo estaba obligado a transcribir un fragmento de una película titulada The Truman Show. El grupo HSG tenía los guiones antes de empezar a transcribir la sección, el CSG recibió los guiones en clase, y el NSG recibió entrenamiento habitual sin los guiones. El rendimiento en el post-test reveló una diferencia significativa entre los grupos con el mejor logro para la CSG. Más específicamente, estas diferencias se indican (a) el uso de guiones pueden mejorar la comprensión auditiva de una L2 y (b) el momento más adecuado de entregar scripts parece ser después de la finalización de la tarea de transcripción.

Palabras clave: Comprensión auditiva, de película, scripts , desempeño de tareas, la transcripción. 


\section{INTRODUCTION}

With the advent of technology in the 1980s, integration of visual materials in language classrooms has become widespread (Vanderplank, 2010). In addition, with the inception of communicative approaches and utilization of more authentic texts (Gilmore, 2007) the need to find a good way to exploit audiovisual materials to their full potential has been urgently felt. In recent years, therefore, with well equipped Language laboratories and classrooms, it is increasingly hard to find an audio only listening presentation.

Besides, satellite programs, feature films, talk shows and so forth have become a daily part of people's life and more off-air authentic visual recordings have found their way into language classrooms, consequently, using a DVD player or a computer have been a common practice in most of language institutes nowadays. As a result, language teaching experts have been encouraged to make the best use of available technology instead of normally using them as another form of a cassette player for playing the audio materials only. But soon it has become clear that without a help option, understanding these ungraded materials is very cumbersome, as most learners lacked sufficient linguistic knowledge (Flowerdew \& Miller, 2005). To compensate for this problem, the use of subtitles, captions and scripts have been suggested, since they could assist learners by allowing dual processing of input (Field, 2004), and in case of comprehension breakdowns, reading the subtitles could help understanding (Garza, 1991).

However, before reviewing research literature, it is worth defining the three major concepts (subtitles, captions and movie scripts or transcripts) that will be broadly used in this paper. Then, in the following section, the theoretical framework of teaching listening will be elaborated on thoroughly.

By subtitles we mean the words printed over a film either in a foreign or the same language to mention what is being said by the actors. And by captions we mean the words printed above or below a picture in a book or newspaper or on a television screen to explain what the picture is showing. And by movie scripts (or transcripts) we mean the written or printed copy of movie conversations or dialogs.

\section{Approaching listening}

Second language experts have always been dealing with three models in this regard. The first model of teaching listening is referred to as the bottom up approach. In this view, verbal text is only regarded as a set of degradable components which the listener must recognize well enough to be able to decode the text. According to this model, the listener builds up understanding by starting with the smallest units of the acoustic message i.e. individual sounds. These are then combined into words which in turn together make up phrases, clauses, and sentences. And in the end, 'individual sentences are combined to create ideas and concepts and relationships' (Flowerdew and Miller, 2005: 24). The second model is called top down approach. In this perspective a holistic outlook to teaching listening is adopted. According to Vandergrift (2007) prior knowledge and metacognitive development play a significant role in interpreting the sequence of words. By metacognitive development, he means "raising learners awareness of listening comprehension process which consequently 
guides them through the process by engaging them in the use of prediction, monitoring, evaluating and problem solving that is critical for the development of self regulated listening" (Vandergrift, 2007: 7).

Finally, the interactive approach to listening comprehension was put forth. This is the view advocated and implemented in this study. The advocates of the interactive model claim that there must be an amalgamation of bottom up and top down approaches in order to effectively and efficiently interpret the text. The model was put forth and developed most notably by Rumelhart (1975). According to Rumelhart, whose theory was developed within the context of reading but which applies equally well to listening, language is processed simultaneously at different levels (Flowerdew and Miller, 2005). This means that knowledge of language components would work in tandem with prior knowledge and strategic use of language to lead the listener to interpret the verbal text which $\mathrm{s} /$ he encounters. The major advantage of interactive model compared to the hierarchal models (bottom up or top down) as Flowerdew and Miller (2005) pointed out is that it allows individual variation in linguistic processing. And 'from the pedagogical perspective this opens up the possibility of a model that is sensitive to individual learning styles' (p. 27). Hence, the learners can take advantage of one more than the other according to their learning styles and preferences.

\section{REVIEW OF LITERATURE}

There is a significant number of research publications on the efficacy of subtitles and captions; nevertheless, to be concise, examples discussed will be limited. In a study conducted by Neuman and Koskinen (1992), the theory of "comprehensible input" was investigated. 129 seventh and eighth graders, who were mostly advanced learners, were assigned into different groups. The study was conducted in 12 weeks with the students watching nine 5 to 8 minute segments of a science production. The result of the study revealed a significant gain for the captioned group compared with the traditional watching TV group, and the reading while listening group. To obtain the results a set of gradually more complex tests was used. The outcome of the study showed that the captioned TV group performed consistently better than the non-captioned group.

Guillory (1999) also investigated different types of captioning. In a six week period experiment, 202 French learners were randomly assigned into three groups (full captions, keyword captions and no captions), and were shown two video clips. Immediately after the experience, all participants completed a short-answer comprehension test consisting of seven questions in English for each video. The results supported full captioning as the most effective procedure pursued by keyword captioning, and the least effective was no captioned text. However, in the post-hoc analysis no significant difference between the full captions group and the keyword captions group was demonstrated.

In addition, the effect of multimodality on listening comprehension was touched upon by Guichon \& McLornan (2008). They compared four groups of French learners. Group 1 was exposed to audio text alone, the second group was confronted with image and sound, the third group was confronted with image, sound and L1 subtitles and the last group had the combination of image, sound and L2 subtitles. The finding of their study was in favor of the last group and also found L2 subtitling more effective. 
Hayati and Mohmedi (2011) also examined the efficacy of subtitled movies on the listening comprehension of 90 intermediate English learners. They used six episodes (approximately 5 minutes each) of a DVD entitled Wild Weather. All subjects were trained by one of these three procedures: English subtitles, Persian subtitles, no subtitles. The results of six sets of multiple choice tests revealed that the English subtitles group performed better than the Persian subtitles group, which in turn performed at a substantially higher level than the no subtitles group.

Finally, Latifi, Mobalegh and Mohammadi (2011) tried to capture the effects of movie subtitles on the immediate and long term improvement of listening comprehension. They used 36 intermediate learners assigned into three groups: English Subtitles Group, Persian Subtitles Group and No-Subtitles Group (NSG). All of the participants' immediate comprehension was measured by a MC teacher made test at the end of each session, and their long term listening improvement was assessed by means of an IELTS test as post test. The results revealed that regarding immediate comprehension, both subtitles groups outperformed the NSG; however, on the IELTS test which measured the long term improvement of the learners the No subtitles group performed significantly better. Despite the immense support for using captions and subtitles, some scathing criticisms have been leveled against their efficacy in improving actual listening comprehension ability. One of the major criticisms in this regard, concerns the idea that improvement in comprehension by the usage of captions and subtitles is somewhat attributed to reading comprehension rather than listening. According to Danan (2004), research found the use of captions unsuitable for those with poor reading ability. Also, in a study by Caimi (2006) students mentioned that during the task, their concentration was primarily on reading rather than on listening, and some of the subjects could not manage reading, listening and watching simultaneously.

The second disadvantage of using subtitles is attributed to the distraction which is caused by reading. Taylor (2005) in his research on three and one year old Spanish learners, found the no-captioned group performing significantly better in comparison to the captioned group. Some of the learners found the captions distracting and were perplexed by the simultaneous multimodal language presentation. The study also suggested that for less proficient learners, captions may have an adverse effect.

As a final point, the major challenge of using subtitles and captions, according to Robin (2007), is that the L2 listeners get accustomed to written support to comprehend the text and not much gain in the actual listening comprehension ability is made. But Markham (1999) tried to challenge this idea. In his study, Markham used two video footages, and divided 118 advanced learners into roughly equal, with or without captions groups. The results of the study revealed that the captioned group outperformed the non captioned group in recognizing words from the passage. This led to the conclusion that the use of captions boosts listening ability. However, this cannot be convincing evidence for listening comprehension improvement, since recognition can perhaps be attributed to memorization rather than listening ability enhancement. Besides, as the findings of the study by Latifi et al (2011) revealed, movie subtitles only boosted the immediate comprehension of the participants. But in the general listening improvement test and its long term effect, the subtitles groups were outperformed by No subtitles group. This was attributed to the fact that "reading the subtitles merely enhanced the comprehension, not their listening ability" (p. 27).

Overall, the three major challenges that were mentioned above raise serious concerns over the efficiency of movie subtitles and captions in improving actual listening comprehension 
ability of the learners. In addition, these shortcomings can even question the validity of data in the previous studies, since as mentioned by Latifi et al (2011) movie subtitles may merely improve the immediate comprehension of the listeners by reading them either in their native language or in a second language. Thus, the main goal of using subtitles which is improving the actual listening ability of the learners seems to be left untouched. Thus, the present study tries to overcome these problems by exploiting an alternative approach to subtitles which is using movie scripts instead. Since movie scripts have the same advantages of subtitles, and don't suffer the setbacks of simultaneous display (hence causing distraction), and reading while listening (which improves only immediate comprehension and not listening ability). Therefore, this study tried to address this gap and find out the possible effects of movie scripts on improving listening comprehension ability of the language learners.

\section{RESEARCH QUESTIONS}

1- Is there any difference between the Scripts Group and the No-scripts Group in terms of listening comprehension achievement?

2- Is there any difference between the Home Scripts Group and the Class Scripts Group in terms of listening comprehension improvement?

\section{Method}

A quasi-experimental pre-test treatment post-test design was used in the current study.

\subsection{Participant}

The participants were recruited from among learners enrolled in fall English classes at Sadr language center. Initially, 105 learners registered for the intermediate classes. To make sure of their homogeneity a listening section of an IELTS test was administered. From among those enrolled, only 45 (out of 105) who had achieved the intermediate level band score were selected. They were then divided into three groups: A Home Scripts Group (HSG), a Class Scripts Group (CSG), and a Non Scripts Group (NSG).

\subsection{Pre-test and post-test}

All subjects sat an actual IELTS test (taken from past papers and only the listening part). Two different listening parts of IELTS exams were used: one as the pretest and the other as the posttest. 


\section{Materials}

\subsection{DVD player}

A DVD player along with a 42 inch LCD set was used in this study to screen the movie during each session in the classroom.

\subsection{Movie}

A movie entitled The Truman Show on a standard DVD quality format was used to ensure the high quality of sound for the participants. The philosophy behind using this movie was twofold:

First, video has long been used in the second language (L2) classroom, especially with the teaching of L2 listening ability, in the belief that including the non-verbal components of a spoken text will be useful for listeners in comprehending the aural input (Wanger, 2010). There are reasons to support this improvement and some of them will be discussed below; (a) The use of video texts allows listeners to view the kinesic behavior of speakers. RafflerEngel (1980) argued that kinesic behavior is an important form of input accompanying spoken texts because it is another way in which language is redundant. The gestures, facial expressions, and visible stress patterns of the speaker serve to reinforce the linguistic message. When the risk of making speaking errors (and consequently hearing misrepresentations) becomes greater, the number of gestures and other kinesic behaviors used by a speaker increases.(b) The use of video texts with listening tasks might influence listeners' attitudes and affect. Researchers have investigated students' perception of the use of video with L2 listening test tasks, and most have found that students prefer the use of video over audioonly texts (Wanger, 2002). And (c), videos can improve inputs by providing visuals, thus enabling listeners to have recourse to acoustic and visual working memory which, in turn, the visual stimuli may influence their cognitive listening process.

Second, the movie was chosen because in the analysis of the discourse of The Truman Show the dialogs were usually in Standard American English and shared the characteristics of standard pronunciation and regular discourse patterns. Besides, the genre of the movie was comedy-drama, and most of the participants were fond of either comedy or drama. Therefore, the movie was appealing to almost all of the participants which is an important factor to keep them motivated to work on the listening materials (Weyers, 1999).

\subsection{Movie Scripts}

Movie scripts for The Truman Show were retrieved from the internet, checked against the actual dialogs of the soundtrack and were printed out to be handed over to the participants. There scripts were divided into 22 parts according to the 22 sections of the movie which were prepared for the participants. 


\section{The PROCEDURE}

This study was conducted during a fall English course, lasting 9 weeks with 3 sessions per week. Before the start of the course, a listening section of an IELTS test was administered as pretest. From all the recruits, 45 learners, who were at intermediate level according to pre-test, were selected. The selected learners were assigned into three equal groups: a Home Scripts Group (HSG), a Class Scripts Group (CSG), and a Non Scripts Group (NSG), each having 15 learners. Then, an authentic feature film entitled The Truman Show was chosen based on some pre-specified criteria (see the previous section). The movie was, then, segmented into 22 sections with two different timings (two minute sections and four minute sections). The reason behind different timing will be explained in the following parts.

To carry out the study, the same procedure was followed in the first session for all groups. All participants watched the complete movie to obtain a general idea of the story. Then, from the next session onward, each group underwent the following treatments which will be explained one by one: HSG: The participants in HSG received a 2 minute section of the movie along with its scripts every session.

At home: They were instructed to watch the 2 minute section at home and transcribe it in their notebooks. However, they were not allowed to look at the scripts before transcribing the part. The subjects were instructed to transcribe the 2 minute section, sentence by sentence while watching. If they could not understand the dialogs or could not comprehend some of the words used, first, they were required to replay that part several times (four or five times). However, if the subjects were unable to comprehend a sentence in part or whole, they were allowed to look at the script of only that particular sentence to check their understanding. This procedure was followed until the end of the transcription task. Transcribing these 2 minute parts would usually take 90 minutes. The timing was obtained through piloting the transcription task by some similar language learners. The pilot group participants were instructed to watch and transcribe the movie as much as they could in 90 minutes. They managed to transcribe almost 2 minutes in due time in average; therefore, the movie was segmented in 2 minute sections.

In the class: Afterwards, in the next session, the 2 minute part that the participants had worked on at home would be played for an intensive analysis as follows:

First, the movie was displayed and the subjects were required to provide a summary. After that, the participants were expected to share their understanding. Then, the sentences were worked on word-by-word and all new words and idiomatic expressions were explained. However, before providing the meaning of new words, the participants were encouraged to guess their meaning from the context. They were taught how to exploit the context to this purpose. If the students failed to make a correct guess, the teacher would impart the meaning. If there were any new grammatical structures, they would also be explained. In addition, specific characteristics of the spoken language, e.g. contractions and elision, were elaborated on. The same procedure was followed in each session throughout the term. CSG: The CSG participants also received a 2 minute section of the movie every session (However, they didn't have the scripts at home unlike HSG).

At home: They were required to watch the section at home and transcribe the dialogs. They were instructed to replay each sentence several times, (four or five times), when they were unable to comprehend the sentence in part or whole. If they couldn't notice the missing 
words after several replays, they would leave a blank and move on to the next sentence. The subjects were required to complete the task in at most 90 minutes.

In the class: For the next session, the scripts of the section were handed to the students and the two minute section of the movie was displayed afterwards. Then, the participants were required to give a summary and share their comprehension. Subsequently, the teacher would work intensively on that 2 minute part verbatim.

All new vocabularies, idiomatic expressions, and grammatical expressions were also explained. However, before providing the learners with the meaning of new words, the participants were encouraged to guess the meaning of those words by using the context. If none of the students could guess correctly, the teacher would provide the meaning. By the end of the class, the students were able to compare their transcriptions with the scripts and find out what they had missed. As with the HSG, specific characteristics of spoken language were described to familiarize the participants with the features of real life speaking. The same procedure was followed in each session throughout the term. The comparison of the students' transcriptions and the movie scripts would provide an opportunity for full comprehension. In this way, the students would be able to evaluate their performance in class and compare the gist of what they had comprehended with the content of the scripts (Cross, 2009).

NSG: For the NSG a different movie segmentation procedure was used (4 minutes for each section). The reason for this different timing of the segments was to avoid any bias in favor of the HSG and the CSG and to equalize the training time for all groups. For they didn't not work on the movie word by word during the class time. As the average listening activity for HSG and CSG was 40 minutes in each class during the piloting it was noticed that in order to have the same amount of class activity time the length of each section must be doubled for the NSG group. Besides, as the duration of each section was 4 minutes, the learners must have worked faster at home to finish the transcription task on time (in 90 minutes). Therefore, they were instructed to replay the sentences two or three times at most (compared to 4 or 5 times for the other groups).

At home: Every session the NSG received a 4 minute section of the movie to be transcribed at home. However, the transcription task was required to be completed in 90 minutes. The participants of the NSG were instructed to transcribe the sections with the same directions as the other groups. All sentences had to be written down verbatim. If they could not understand the sentence content, they were required to replay it two or three times at most (to complete the task in due time), and If they were unable to understand the missing part(s), they could leave a blank.

In the class: In the next session, however, a different training procedure was utilized as no scripts were made available to the participants. First, in each session the 4 minute section would be played part by part. Then the participants would be reported? Would report? their comprehension of that part. In case of non-comprehension or miscomprehension, the part would be replayed until they could understand what had happened generally, and subsequently at the end of the 4 minute section, the general theme of that section would be discussed. As in the case of the other groups, new words, idiomatic expressions and grammatical points were taught. Likewise, the subjects were required to guess the meaning of new words first by using the context. If no logical guess was made, the teacher would provide the definition. In addition, the distinguishing features of the spoken language were explained. The specific procedure for each group was followed for 24 consecutive sessions. 
By the end of the term, all participants were post-tested with an IELTS test. In addition, at the end of the study, an interview was carried out to ascertain the participants' opinions about the use of scripts in practicing listening.

\section{Data analysis}

As for the data analysis, the students' scores on pre-and posttest were calculated according to answer keys provided by Cambridge IELTS books, and the subjects' performance was compared using a $t$-test and a one way ANOVA.

\section{The effect of scripts on listening comprehension}

The first research question concerned whether there is any difference between the Scripts group and the No-Scripts group. In this study, there were two Scripts groups (one HSG and one CSG) each having 15 learners which amounted to 30 overall. The two groups were combined to form one Scripts group for the purpose of data analysis. We also had one No-Scripts Group with 15 learners. To answer this question, an independent sample $t$-test was run to compare the performance of Scripts and Non Scripts groups. Figure 1 and Table 2 provide the group statistics along with the results of the $t$-test.

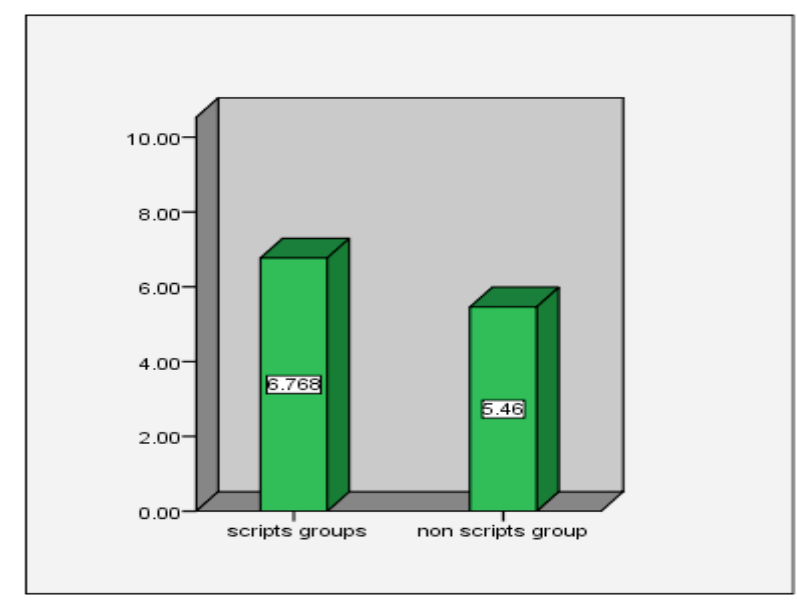

$\square$ posttest

Figure 1. Mean total Scores of the Scripts and Non-Scripts Groups.

As illustrated in Figure 1, the subjects in the Scripts group gained a higher mean score on the posttest after receiving the treatment $(6.76>5.46)$. However, in order to find significance of the differences, the results of the $t$-test must be considered. 
Table 1: Independent T-test results for mean difference of Scripts and Non-Scripts groups

\begin{tabular}{|c|c|c|c|c|c|c|c|c|}
\hline & & & Sig. & $\mathrm{T}$ & $\mathrm{df}$ & $\begin{array}{l}\text { Sig. } \\
\text { (2-tailed) }\end{array}$ & $\begin{array}{l}\text { Mean } \\
\text { Difference }\end{array}$ & $\begin{array}{l}\text { Std. Error } \\
\text { Difference }\end{array}$ \\
\hline pretest & $\begin{array}{l}\text { Equal variances } \\
\text { assumed }\end{array}$ & .351 & .557 & -.379 & 43 & .706 & -.01667 & .04393 \\
\hline posttest & $\begin{array}{l}\text { Equal variances } \\
\text { assumed }\end{array}$ & 19.586 & .000 & 6.817 & 43 & .000 & 1.30833 & 19192 \\
\hline
\end{tabular}

As Table 1 indicates, the groups' performance on pre-test shows no significant difference $(T(43)=-.397$ and $P=.706)$. However, their performance on the posttest demonstrated a significant gain $(T(43)=6.81$ and $P=.000)$. It can be maintained that using movie scripts exercised a positive impact on the listening comprehension improvement of the L2 learners. Moreover, to ensure the significance of the data, the Effect Size was calculated $(=.51)$ using Eta squared formula. And according to guidelines proposed by Cohen (1988) the demonstrated effect size (.51) is considered large.

\section{Time of exposure}

The second research question concerned whether there is any difference between the HSG and the CSG in terms of listening comprehension improvement. To answer this question and to analyze the differences between the three groups thoroughly, a one way ANOVA and a Scheffe post-hoc were conducted.

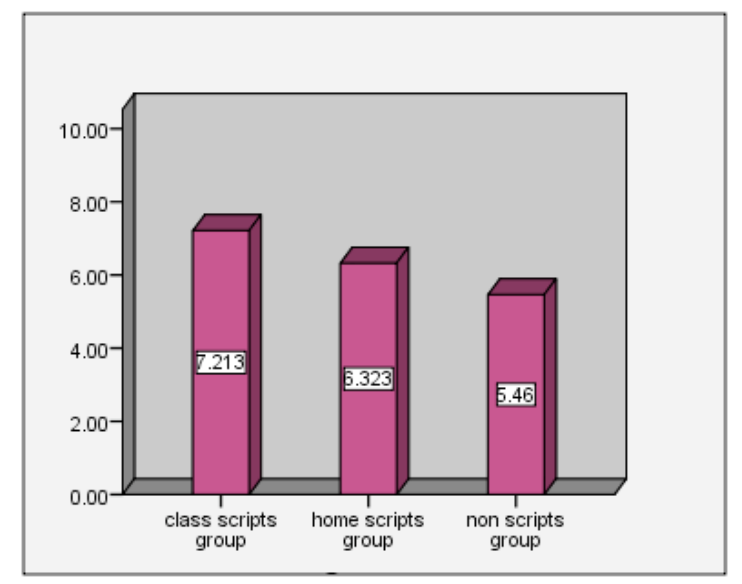

Figure 2: Mean scores in percentages of performance of all groups

As shown in Figure 2, the learners who received the scripts in the class have a better mean score compared to the learners who had the scripts at home $(7.21>6.46)$. In addition, they both had a better mean score than the NSG (5.46). However, to grasp a better un- 
derstanding of the significance of the data, the results of the one way ANONA and Scheffe post-hoc must be considered.

Table 2. ANOVA results for the mean difference of the groups

\begin{tabular}{lllllll}
\hline \multirow{2}{*}{ Posttest } & & Sum of Squares & df & Mean Square & F & Sig. \\
\cline { 2 - 7 } & Between Groups & 23.058 & 2 & 11.529 & 48.923 & .000 \\
\cline { 2 - 7 } & Within Groups & 9.898 & 42 & .236 & & \\
\hline
\end{tabular}

Table 3: scheffe post hoc analysis of all groups

\begin{tabular}{lllll}
\hline \multirow{2}{*}{ I) Groups } & (J) Groups & Mean Difference (I-J) & Std. Error & Sig. \\
\hline Class Scripts Group & Home Scripts Group & $.89000^{*}$ & .17726 & .000 \\
\cline { 2 - 5 } & Non-Scripts group & $1.75333^{*}$ & .17726 & .000 \\
\hline \multirow{2}{*}{ Home Scripts Group } & Class Scripts Group & $-.89000^{*}$ & .17726 & .000 \\
\cline { 2 - 5 } & Non-Scripts group & $.86333^{*}$ & .17726 & .000 \\
\hline \multirow{2}{*}{ Non Scripts Group } & Class Scripts Group & $-1.75333^{*}$ & .17726 & .000 \\
\cline { 2 - 5 } & Home Scripts Group & $-.86333^{*}$ & .17726 & .000 \\
\hline
\end{tabular}

Table 3 shows a significant difference in the scores obtained from the three groups $(F$ $(2,42)=48.92, P=000)$. Yet, to determine where the differences lie, the post hoc analysis must be taken into account.

As indicated in table 4, the CSG performed significantly better than the HSG ( $\mathrm{P}=000)$. This might suggest that the best time of handing the scripts to the listeners would be after finishing the transcription task. Besides, the other fact that is noticeable in Table 4 is that the HSG also outperformed the NSG.

\section{Discussion}

Results of the present study provided evidence that exposing English learners to movie scripts exercises a positive effect on their listening comprehension skills and ability. The answer to the first research question, concerning whether there is any difference between the Scripts Group and the No-scripts Group in terms of listening comprehension achievement was in favor of the script groups. As it was revealed by analysis of the data, the script group learners benefited from the exploitation of movie scripts because they could gain proficiency by the meticulous analysis of the movie in the class. They could become familiar with the features of authentic language and be exposed to more practical vocabularies and structures. Therefore, as acknowledged by the participants, they could understand the spoken language better at the end of the study. They mentioned that they gave up the habit of reading 
subtitles instead of listening for meaning as it was their common practice to improve their listening in the past. In addition, the strategies of guessing the new words from the context and not overloading their working memory with unfamiliar words and structures could help them manage the flow of information more easily. They were taught not to be obsessed with understanding every single word. The participants in the survey also commented that at the beginning of the study it was hard and scary for them to be exposed to authentic movies, but with the help of scripts they managed to improve their listening ability.

To be more precise, a possible explanation for the significant improvement of the Scripts group may be attributed to the interactive model of teaching used in this study. In accordance with Vandergrift (2007), the amalgamation of bottom up and top down processing results in a greater improvement, as most non native listeners are inclined to utilize top down processing only, and neglect the importance of bottom up processing (Field, 2004). Also in line with what Hulstjin (2003) proposed, a good listening course must include tasks that in addition to emphasizing top down processing, put effort into improving bottom up processing as well. Therefore, it may be logical to posit that the combination of top down activities, such as guessing new words from context, and the intensive analysis of the scripts (bottom up) used in this study, possibly resulted in the listening comprehension improvement of the learners.

The importance of learners' competence in exploiting top down strategies to process the flow of information is hard to neglect as overloading short-term memory by attending to every single word can cause the listener to lag behind in comprehension (Celce-Murcia, 2001). However, a question may arise as to how the L2 learners' bottom up processing ability is related to enhancing listening. This question may be answered if one considers the issue of automaticity. Automaticity in processing language components can free up learners' working memory capacity and therefore let them process information more accurately (Field, 2008). Consequently, acquiring automaticity in bottom up processing can pave the way for easier higher level information processing (top down) since the learners are able to process the text without effort at lower levels of word recognition and sentence parsing (Hulstijn, 2003). In agreement with the mentioned advantages, in the interview conducted at the end of the study, the Scripts group subjects believed that intensive work on the scripts helped them process information more easily. The participants said that they could overcome some of their problems in various aspects of language components such as structures and vocabularies in this way.

Automaticity in bottom up processing may not only be gained by acquiring a good command of previously acquired knowledge, it can also be possibly improved by acquiring new information (Hulstijn, 2003). In Hulstijn's view, vocabulary acquisition and the automatization of word-by-word understanding are the two most crucial factors contributing to language acquisition, hence automatization. As the participants stated in the interview, they learned more structures and words by working intensively on the scripts and the knowledge gained helped them achieve better results in the post-test. This is in accordance with William and Throne's (2000) study, concluding that when students are required to provide subtitles for movie clips it leads to a significant improvement in the subjects' language proficiency.

Besides, by considering acquisitional aspects, in a way, the results seem to accord with Vanderplank (1988), stating that 'subtitles might have potential value in helping the language acquisition process by providing learners with the key to massive quantities of authentic 
and comprehensible input' (pp. 272-273). However, the distinguishing feature of using scripts in this study is that the written input was not simultaneously used with audiovisual input. This time difference in script presentation could possibly compensate to some degree for the shortcomings of simultaneous presentation (see the review of literature section). The findings of the present study regarding the second research question "whether there is any difference between the Home Scripts Group and the Class Scripts Group in terms of listening comprehension improvement" revealed that the participants in the CSG did much better compared to those in the HSG.

A possible explanation for the results could be the availability of the scripts to the learners at home. As some of the HSG learners mentioned during the semester, the presence of scripts could deter them from trying hard. When encountering a difficult part of the movie, they would prefer to consult the scripts. From this perspective, the availability of scripts at home was to some extent similar to using subtitles, the only difference being that the scripts were used with a time delay. Thus, in line with Danan (2004) and Zanon (2006) this immediate support may lead to laziness and could hinder deep processing of input. However, the follow-up activities which the learners carried out in class could partly compensate for some of the shortcomings and this may explain the significant listening improvement of the HSG compared to the NSG.

\section{Conclusion}

The present study attempted to investigate the effects of using movie scripts on improving the listening comprehension ability of language learners. The findings favored using movie scripts as a way of improving listening comprehension, and the idea that the best time to use scripts may be in class when learners have finished the transcription task. This research supports the use of movie scripts as an alternative approach to movie subtitles and captions. Besides, the interactive model of teaching listening comprehension was advocated as well.

\section{Pedagogical implications}

With respect to second language comprehension, this study has found that delayed presentation of scripts can lead to increased listening comprehension. It may be suggested that by using movie scripts, input is processed more deeply because the L2 learners can automatize their knowledge of language.

Also, this study suggests a new way of teaching listening. As judged from the results, it would apparently be beneficial in L2 instruction to work on scripts as a medium of gaining language proficiency in its natural setting. The movie scripts may offer students some knowledge of language (words, structure) in addition to its natural context of use. 


\section{LiMITATIONS OF THE STUDY AND SUGGESTION FOR FURTHER RESEARCH}

One of the limitations of the present study was that there was no control over the HSG. That is, there was no assurance of the idea of whether or not they looked at the scripts during the transcription task at home. Moreover, there was no guarantee that all subjects performed the task in due time (90 minutes).

It must be noted that, generalizability of the findings is limited due to the small sample size (15 each group) and participation of intermediate learners only. Further studies are required to investigate the effect of movie scripts on different proficiency levels.

\section{REFERENCE}

Caimi, A. (2006). "Audiovisual translation and language learning: The promotion of intralingual subtitles", in The Journal of Specialized Translation, 6: 85-98.

Celce-Murcia, M. (3 $3^{\text {rd }}$ ed) (2001). Teaching English as a Second or Foreign Language. Boston: Heinle \& Heinle.

Cross, J. (2009). "Effects of listening strategy instruction on news videotext comprehension", in Language Teaching Research, 13, 2:151-176.

Danan, M. (2004). "Captioning and Subtitling: Undervalued Language Learning Strategies", in Translators' Journal, 49, 1: 67-77.

Field, J. (2004). “An insight into listeners' problems: Too much bottom-up or too much topdown?", in System, 32: 363-377.

Field, J. (2008). "Looking outwards, not inwards", in ELT Journal, 61, 1: 30-38.

Flowerdew, J. \& L. Miller (2005). Second language listening: Theory and practice. New York: Cambridge University Press.

Garza, T. (1991). "Evaluating the use of captioned video materials in advanced foreign language learning”, in Foreign Language Annal, 24,3: 239-258.

Gilmore, A. (2007). "Authentic materials and authenticity in foreign language learning", in Language Teaching, 40,2: 97-118.

Grgurovi, M. \& Hegelheimer, V. (2007). "Help options and multimedia listening: students' use of Subtitles and transcripts", in Language learning and technology, 11,1: 45-66.

Guichon, N. \& McLornan, S. (2008). "The effects of multimodality on L2 learners:Implications for CALL resource design", in System, 36,1: 85-93.

Guillory, H.G. (1999). "The effect of keyword captions to authentic French video on learner comprehension", in CALICO Journal, 15: 89-108.

Hayati, A. and Mohmedi, F. (2011). "The effect of films with and without subtitles on listening comprehension of EFL learners", in British Journal of Educational Technology, 42,1:181-192.

Hulstijn, J. H. (2003). "Connectionist models of language processing and the training of listening skills with the aid of multimedia software", in Computer Assisted Language Learning, 16,5: $413-425$.

Latifi, M., Mobalegh, A. and Mohammadi, M. (2011). "Movie Subtitles and the Improvement of Listening Comprehension Ability: Does it help?", in Journal of Language Teaching and Learning, 1, 2: 18-29.

Markham, P. L. (1999). "Captioned videotapes and second-language listening word recognition", in Foreign Language Annals, 32,3: 321-328. 
Markham, P. (2000-2001). "The influence of culture-specific background knowledge and captions on second language comprehension", in Journal of Educational Technology Systems, 29,4: 331-343.

Neuman, S. B. and P. Koskinen. (1992). "Captioned television as 'comprehensible input': Effects of incidental word learning from context for language minority students", in Reading Research Quarterly, 27: 95-106.

Raffler-Engel, W. (1980). "Kinesics and paralinguistics: A neglected factor in second language research and teaching", in Canadian Modern Language Review, 36: 225-237.

Robin, R. (2007). "Learner-Based Listening and Technological Authentic it", in Language Learning and Technology Journal, 11,1: 109-115.

Rumelhart, D.E. (1975). "Notes on a schema for stories", in D.G. Bobrow and A. Collins (eds.), Representation and understanding: Studies in cognitive science. New York: Academic Press.

Taylor, G. (2005). "Perceived processing strategies of students watching captioned video", in Foreign Language Annal, 38,3: 422-427.

Vandergrift, L. (2007). "Recent developments in second and foreign language listening comprehension research", in Language Teaching, 40: 191-210.

Vanderplank, R. (1988). "The value of teletext subtitles in language learning", in ELT Journal, 42,4: 272-281.

Vanderplank, R. (2010). "Deja vu? A decade of research on language laboratories, television and video in language learning", in Language teaching, 43,1: 1-37.

Wagner, E. (2002). "Video listening tests: A pilot study", in Working Papers in TESOL \& Applied Linguistics, Teachers College, Columbia University, 2,1.

Wagner, E. (2010). "The effect of the use of video texts on ESL listening test-taker performance", in Language Testing, 49,2: 1-21.

Weyers, J.R. (1999) "The effect of authentic video on communicative competence", in The Modern Language Journal, 83: 339-49.

Williams, H. \& D. Thorne (2000). "The value of teletext subtitling as a medium for language learning", in System, 28,2: 217-228.

Zanon, N.T. (2006). "Using subtitles to enhance foreign language learning", in Porta Linguarum, 6: $41-52$. 